\title{
Avaliação de impacto de políticas públicas: o estudo de caso do PIBIC/ICMBio no Brasil
}

\author{
Policy Impact Assessment: \\ The PIBIC/ICMBio Case Study in Brazil
}

\begin{abstract}
Heloisa de Camargo Tozato ${ }^{1}$
${ }^{1}$ Universidade de São Paulo | Instituto de Estudos Avançados - Grupo de Pesquisa Políticas Públicas, Territorialidade e Sociedade | São Paulo | SP | Brasil. Contato: htozato@gmail.com.

ORCID: http://orcid.org/0000-0002-5417-8985

Fernanda de Araújo Bezerra ${ }^{2}$

${ }^{2}$ Instituto Chico Mendes de Conservação da Biodiversidade | Coordenação de Pesquisa e Gestão da Informação sobre Biodiversidade | Brasília | DF | Brasil. Contato: fernanda.bezerra@icmbio.gov.br. ORCID: http://orcid.org/0000-0002-0160-3810
\end{abstract}

Elizabeth Maria Maia de Albuquerque Martins ${ }^{3}$

${ }^{3}$ Instituto Chico Mendes de Conservação da Biodiversidade | Coordenação de Pesquisa e Gestão da Informação sobre Biodiversidade | Brasília | DF | Brasil. Contato: elizabeth.martins@icmbio.gov.br. ORCID: http://orcid.org/0000-0003-1558-294X

Ana Elisa de Faria Bacellar ${ }^{4}$

${ }^{4}$ Instituto Chico Mendes de Conservação da Biodiversidade | Centro Nacional de Avaliação da Biodiversidade e de Pesquisa e Conservação do Cerrado | Brasília | DF | Brasil. Contato: ana.schittini@icmbio.gov.br. ORCID: http://orcid.org/0000-0001-6659-6060

Ivan Salzo ${ }^{5}$

${ }^{5}$ Instituto Chico Mendes de Conservação da Biodiversidade | Coordenação de Pesquisa e Gestão da Informação sobre Biodiversidade | Brasília | DF | Brasil. Contato: ivan.salzo@icmbio.gov.br. ORCID: http://orcid.org/0000-0001-8257-3010

Rodrigo Silva Pinto Jorge ${ }^{6}$

${ }^{6}$ Instituto Chico Mendes de Conservação da Biodiversidade | Centro Nacional de Avaliação da Biodiversidade e de Pesquisa e Conservação do Cerrado | Brasília | DF | Brasil. Contato: rodrigo.jorge@icmbio.gov.br. ORCID: http://orcid.org/0000-0001-9876-4532

Katia Torres Ribeiro ${ }^{7}$

${ }^{7}$ Instituto Chico Mendes de Conservação da Biodiversidade | Centro Nacional de Avaliação da Biodiversidade e de Pesquisa e Conservação do Cerrado | Brasília | DF | Brasil. Contato: katia.ribeiro@icmbio.gov.br. ORCID: http://orcid.org/0000-0001-7023-7204

Resumo: A avaliação de impacto baseada em evidências apresenta elevado potencial para subsidiar a tomada de decisão, melhorar a implementação das políticas públicas e respaldar a transparência da gestão. Diante desta perspectiva, a presente pesquisa teve como objetivo desenvolvê-la utilizando, como estudo de caso, o Programa Institucional de Bolsas de Iniciação Científica do Instituto Chico Mendes de Conservação da Biodiversidade (PIBIC/ICMBio), o qual completou 10 anos de implementação no país. O Programa constitui a ferramenta do Instituto para explicitar quais conhecimentos ou informações são imprescindíveis para impulsionar as ações de intervenção para a gestão e manejo da biodiversidade brasileira. A avaliação foi realizada a partir da pesquisa documental, da observação participante, da formulação da cadeia de resultados, da consulta a atores-chaves e do desenvolvimento da cartografia temática. Os resultados evidenciaram o alcance dos objetivos do PIBIC/ICMBio; sua relevância para as demais atribuições do próprio ICMBio; sua coerência com as principais políticas brasileiras de fomento e execução programas de pesquisa, proteção, preservação e conservação da biodiversidade e de educação ambiental; sua eficiência em relação aos custos envolvidos; seu valor agregado e sua 
potencialidade para o know-how de apoio a tomada de decisão sobre manejo e conservação da biodiversidade no Brasil.

Palavras-chave: Iniciação científica. Formação socioambiental. Análise de evidências.

Abstract: Evidence-based impact assessment has a great potential to support decision making, improve the public policy cycle and support its transparency. Given this perspective, the present research had the objective of develop it using, as a case study, the Institutional Program of Scientific Initiation Scholarships of the Chico Mendes Institute for Biodiversity Conservation (PIBIC/ICMBio), which completed 10 years of implementation in Brazil. The Program is the ICMBio's tool to clarify which knowledge or information is essential to boost intervention actions for the Brazilian biodiversity management. The evaluation was based on documentary research, participant observation, the formulation of the result chain, consultation with key actors and the development of thematic cartography. The results showed the achievement of the PIBIC/ICMBio objectives; its relevance to other attributions of ICMBio; its coherence with the main Brazilian policies of fomentation and execution programs of research, protection, preservation and conservation of the biodiversity and of environmental education; its efficiency in relation to the costs involved; its added value ; and its potential for the Brazilian know-how to support decision making on biodiversity management and conservation.

Keywords: Undergraduate research. Social and environmental formation. Evidence-based analysis.

- Recebido em: 25 de setembro de 2019 A Aprovado em: 30 de maio de 2020

DOI: http://dx.doi.org/10.1590/S1414-40772020000300009

Este é um artigo publicado em acesso aberto sob uma licença Creative Commons

https://creativecommons.org/licenses/by-nc/4.0/

\section{Introdução}

As políticas públicas constituem dispositivos dos setores da sociedade, provenientes de uma construção coletiva complexa, coordenada por atores sociais (ou grupos de atores), organizações públicas e organizações internacionais (MASSARDIER, 2003). Elas e seus instrumentos regulam as ações concretas de curto, médio e longo prazo e permitem a combinação de estratégias de gestão em diferentes escalas, urgências e intensidades de intervenção.

A avaliação de impacto baseada em evidências integra a formulação de políticas públicas e, diferente das avaliações que se concentram na investigação do que funciona, tais quais os insumos e os produtos imediatos, baseia-se na construção do conhecimento para encontrar evidências críveis sobre o que funciona e também o porquê das intervenções analisadas alcançarem, ou não, o impacto pretendido (GERTLER et al., 2018; WHITE, 1999). Em decorrência desses fatores, o método disponibiliza aos gestores um conjunto de informações convincentes e abrangentes para que possam melhor embasar a tomada de decisão, melhorar o ciclo de políticas públicas e respaldar sua transparência (GERTLER et al., 2018).

De acordo com a Convenção de Diversidade Biológica (CDB), a análise de evidências constitui uma ferramenta para a avaliação do desempenho dos instrumentos de gestão da 
biodiversidade de seus países membros (CBD, 2017). No entanto, apesar de sua relevância para os órgãos de gestão, no âmbito da gestão ambiental, esta abordagem de avaliação ainda é incipiente (BAYLIS et al., 2016). Um exemplo recente de sua utilização foi a avaliação de desempenho das políticas europeias de conservação da natureza pela Comissão Europeia em 2016 (CBD, 2017; EU, 2016; TOZATO, 2016).

No caso do Brasil, apesar de o país ter sido a primeira nação a assinar a CDB durante a Rio 92 e vir aprimorando, desde então, sua legislação ambiental (PRATES; IRVING, 2015), o país carece da condução de estudos de avaliação de impacto baseada em evidências das políticas públicas de gestão da biodiversidade.

Dentre os instrumentos das políticas públicas para a gestão e manejo da biodiversidade brasileira, o Programa Institucional de Bolsas de Iniciação Científica (PIBIC/ICMBio) do Instituto Chico Mendes de Conservação da Biodiversidade (ICMBio) destaca-se por constituir a ferramenta responsável por desenvolver pesquisas orientadas ao problema (KUEFFER et al., 2012), explicitando quais conhecimentos ou informações são imprescindíveis para impulsionar as ações de intervenção no país.

Estabelecido por meio da Portaria $n^{\mathrm{o}} 79$ de 06 de outubro de 2008 com o objetivo de contribuir com a ampliação do conhecimento sobre a biodiversidade, com o fortalecimento da pesquisa para a conservação e com a formação de profissionais que atuarão em prol da gestão socioambiental, o PIBIC/ICMBio completou, em 2018, 10 anos de implementação em território nacional.

Diante deste cenário e considerando a potencialidade da avaliação de impacto baseada em evidências para a transparência e aprimoramento da governança e da gestão de políticas públicas, o objetivo deste estudo foi desenvolvê-la utilizando, como estudo de caso, o Programa Institucional de Bolsas de Iniciação Científica do Instituto Chico Mendes de Conservação da Biodiversidade (PIBIC/ICMBio).

\section{Abordagem metodológica}

A abordagem metodológica do presente estudo foi estruturada no âmbito da análise de evidências baseada em Gertler et al. (2018) e Wxhite (1999). O conjunto de dados qualitativos e quantitativos foi obtido a partir da combinação dos métodos indicados na Figura 1. O período de análise de dados compreendeu os ciclos de implementação do Programa durante 2008 a 2018, sendo que cada um referia-se ao segundo semestre de um ano e ao primeiro do seguinte. 
Figura 1 - Fluxograma das etapas metodológicas da análise de evidências do Programa Institucional de Bolsas de Iniciação Científica (PIBIC/ICMBio) do Instituto Chico Mendes de Conservação da Biodiversidade (ICMBio)

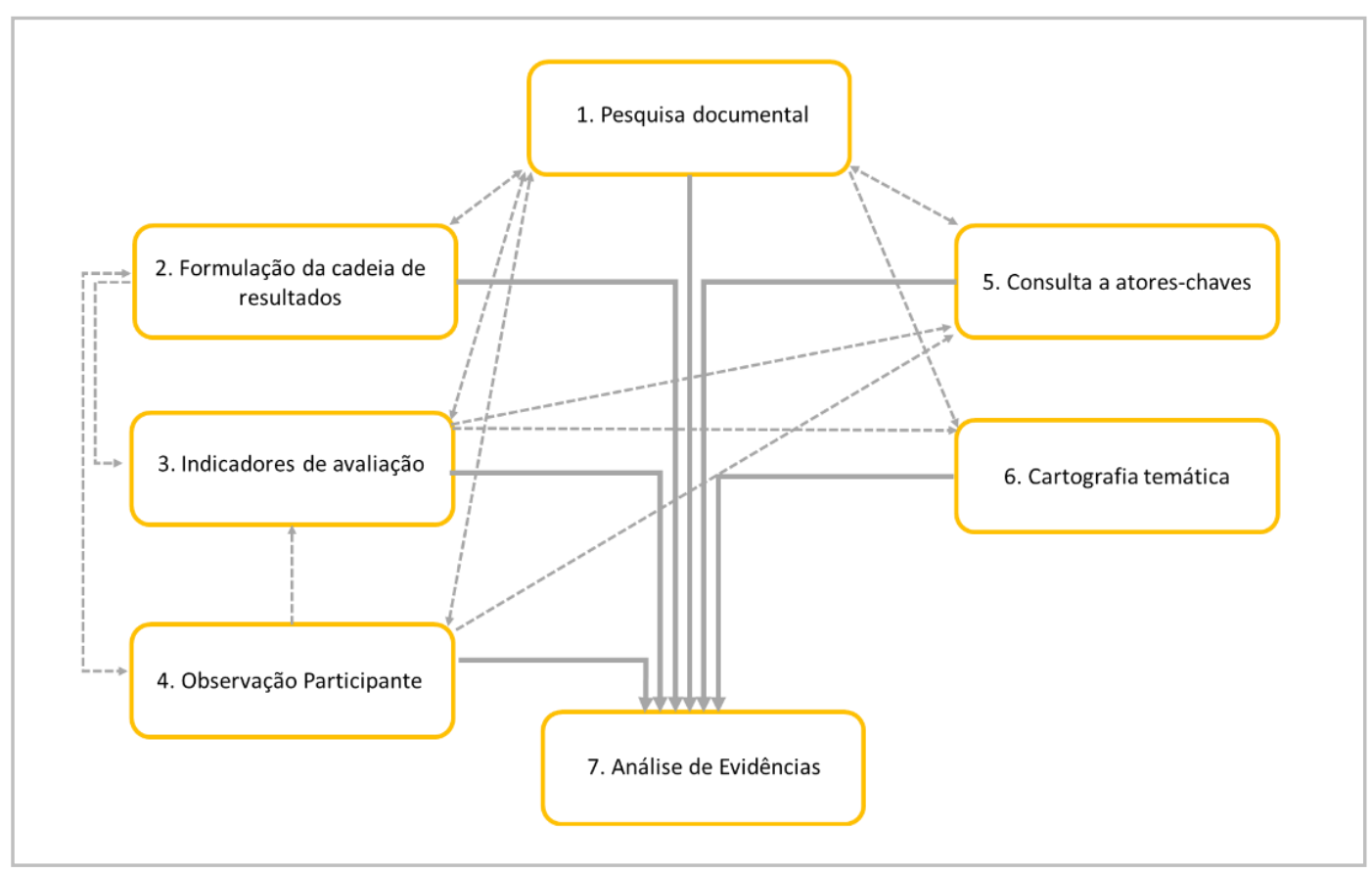

Na Etapa 1 foi realizada a pesquisa documental conforme Moreira (2005). Foram consultados documentos oficiais brasileiros e dados referentes ao monitoramento do Programa realizado pela Secretaria do PIBIC/ICMBio (ICMBIO, 2018). Os parágrafos dos documentos que descreveram ou indicaram alguma posição, ação ou indagação relacionada à implementação do PIBIC/ICMBio foram destacados, lidos novamente, classificados e sistematizados em tabelas.

Foram consultados a Portaria $\mathrm{n}^{\mathrm{o}} 79$, de 06 de outubro de 2008, que estabelece o PIBIC/ICMBIO; a Resolução Normativa $\mathrm{n}^{\mathrm{o}}$ 17/2006 do Conselho Nacional de Desenvolvimento Científico e Tecnológico (CNPq) e seus Anexos II e III, que regulam os programas de iniciação científica vinculados ao CNPq; o Manual do Estudante PIBIC/ICMBio de 2017; a Nota sobre os Resultados e Avaliação da Trajetória Posterior dos Bolsistas do PIBIC/ICMBIO de 2015; os 11 Editais de Seleção do Programa PIBIC/ICMBio aplicados no período de 2008 a 2018; e as nove edições dos Anais do Seminário de Pesquisa e Encontro de Iniciação Científica do ICMBio, dentre outros.

Além deles, foram analisados os perfis profissionais dos 262 estudantes egressos e dos 84 servidores orientadores do programa disponíveis na Plataforma Lattes do CNPq; a participação destes últimos no Diretório dos Grupos de Pesquisa do CNPq; e o Índice Geral de Cursos (IGC) das 66 instituições de origem dos estudantes, disponíveis no Ministério da 
Educação (MEC-INEP). As informações da análise documental possibilitaram estruturar e embasar as demais etapas metodológicas.

Na Etapa 2, a cadeia de resultados do PIBIC/ICMBio foi construída conforme Gertler et al. (2018). As informações da pesquisa documental permitiram a construção prévia de suas categorias de implementação (insumos, atividades e produtos) e de resultados (resultados e impactos). Uma vez estabelecida, a cadeia de resultados possibilitou a identificação de indicadores de avaliação do programa.

$\mathrm{Na}$ Etapa 3, foram selecionados 44 indicadores de avaliação no padrão SMART (em inglês): específicos, mensuráveis, atribuíveis, realistas e direcionados, conforme Gertler et al. (2018). Eles se distribuíram em cinco indicadores sobre insumos, nove sobre atividades, sete sobre produtos e 23 sobre resultados e impactos da implementação do PIBIC/ICMBio no período de 2008 a 2018.

Na Etapa 4 foi desenvolvida a observação participante conforme May (2011) e Gil (1987) no âmbito da Oficina Participativa do PIBIC/ICMBio, realizada no dia 29/11/2018 na sede do ICMBio em Brasília. Participaram da reunião 16 membros atuantes no Programa, sendo eles: o coordenador, membros do comitê institucional, orientadores e servidores de unidades de conservação federais, centros nacionais de pesquisa e conservação e coordenações da sede.

O desenvolvimento da Oficina apresentou enfoque participativo com o uso de técnicas Metaplan. As contribuições foram registradas por meio da utilização de tarjetas coloridas pregadas em painéis para a visualização móvel e fotografadas. Paralelamente, foram reunidas anotações de campo para a construção de um raciocínio concomitante à experiência vivenciada. Uma vez sistematizadas, as contribuições dos atores-chave permitiram aprimorar e legitimar a cadeia de resultados e, por conseguinte, os indicadores de avaliação, bem como realizar a análise contrafactual da existência do PIBIC/ICMBio.

$\mathrm{Na}$ Etapa 5, foram consultados atores-chave do PIBIC/ICMBio conforme Minayo (2002, 2011), sendo 26 estudantes egressos, 20 ex-orientadores do programa, dois ex-membros do Comitê Institucional do Programa, e três ex-membros do Comitê Externo do Programa, todos participantes de um ou mais ciclos de implementação do Programa. A consulta foi realizada por meio de questionários disponibilizados em formulário online Google Forms. As perguntas dos questionários foram elaboradas com base nos indicadores de avaliação identificados na Etapa 3.

Na Etapa 6, que corresponde à cartografia temática (vide THÉRY 1999, ARCHELA; THÉRY, 2008), foram utilizados os dados selecionados a partir das Etapas 1 e 3 para a geração 
de mapas temáticos. A espacialização foi desenvolvida com o auxílio dos softwares QGIS 2.18.27 (QGIS, 2018) e Inkscape 0.92.3 (INKSCAPE, 2018).

Por fim, na Etapa 7, as informações sistematizadas nas etapas anteriores foram integradas para subsidiar a análise de evidências de 10 anos de implementação do PIBIC/ICMBio. Sua lógica de avaliação foi enquadrada nas categorias efetividade, relevância, eficiência, coerência e valor agregado, conforme EU (2016).

Para a análise de efetividade do PIBIC/ICMBio, foi analisado o alcance dos objetivos do Programa e para a de relevância, foi analisado em que medida esses alcances são coerentes com as necessidades do órgão executor, o ICMBio. Para a análise de coerência, foram analisadas as sinergias ou incoerências entre o Programa e as principais políticas nacionais que deveriam funcionar em consonância para o alcance de seus objetivos: a Estratégia e Plano de Ação Nacionais para a Biodiversidade (EPANB), o Programa Institucional de Bolsas de Iniciação Científica - PIBIC do Conselho Nacional de Desenvolvimento Científico e Tecnológico ( $\mathrm{CNPq})$, e a Estratégia Nacional em Comunicação e Educação Ambiental em Unidades de Conservação (ENCEA). Para a análise de eficiência, os custos envolvidos em sua implementação foram analisados com relação aos seus resultados alcançados. Para a análise de valor agregado, foram identificadas as percepções dos participantes do PIBIC/ICMBio a respeito de sua importância e possibilidade de inexistência.

\section{Resultados e Discussão}

\section{O PIBIC/ICMBio: caracterizacão geral}

O Programa Institucional de Bolsas de Iniciação Científica (PIBIC/ICMBio) do Instituto Chico Mendes de Conservação da Biodiversidade (ICMBio) teve início a partir de parceria do Instituto com o Conselho Nacional de Desenvolvimento Científico e Tecnológico (CNPq) em 2008, dentro da qual ambas as instituições passaram a oferecer bolsas de iniciação científica a estudantes de graduação para o desenvolvimento de projetos de pesquisa orientados por servidores do próprio ICMBio (COPEG/ICMBIO, 2018). A iniciativa fora implementada como resposta às atribuições do Instituto em fomentar e executar programas de pesquisa, proteção, preservação e conservação da biodiversidade e de educação ambiental, articuladas com as estratégias de conservação e manejo da biodiversidade, conforme a Lei $\mathrm{n}^{\circ} 11.516$, de 28 de agosto de 2007.

A gestão do PIBIC/ICMBio é realizada pela Diretoria de Pesquisa, Avaliação e Monitoramento da Biodiversidade (DIBIO) por meio da Coordenação de Pesquisa e de Gestão 
da Informação sobre Biodiversidade (COPEG) do ICMBio com o auxílio do Comitê Institucional do Programa, composto por servidores do Instituto e membros externos ad-hoc (COPEG/ICMBIO, 2018).

Seus objetivos específicos são: i) despertar a vocação científica e desenvolver talentos para a pesquisa, mediante a participação de estudantes de graduação em projetos de nível e mérito científico e tecnológico reconhecidos; ii) contribuir com a formação de recursos humanos para a pesquisa em temas ambientais; iii) incentivar a consolidação de uma política de pesquisa e desenvolvimento científico e tecnológico para iniciação científica no ICMBio; iv) estimular servidores a engajarem estudantes de graduação nas atividades de iniciação científica e tecnológica, integrando-os em grupos de pesquisa; e v) contribuir para a expansão e renovação do quadro de servidores atuantes na produção de conhecimento e, consequentemente, estimular o envolvimento de novos orientadores (BRASIL, 2008).

Os orientadores dos trabalhos de iniciação científica constituem servidores do ICMBio atuantes em qualquer instância da instituição, com título de doutor ou perfil equivalente e experiência para a execução de pesquisas em sua área de atuação. Dentre suas atribuições estão a seleção e a indicação dos estudantes que desenvolverão as propostas de pesquisa submetidas ao processo seletivo do Programa; a elaboração do plano de trabalho de iniciação científica dos estudantes; a orientação destes nas distintas etapas da execução do trabalho científico; o apoio na elaboração de produtos; e o acompanhamento das exposições dos resultados dos trabalhos realizados por seus orientandos. Além disso, podem estabelecer parcerias com co-orientadores de universidades ou do próprio ICMBio (COPEG/ICMBIO, 2018).

Os estudantes PIBIC/ICMBio constituem alunos regularmente matriculados em curso de graduação de qualquer instituição de ensino superior do país. Dentre os compromissos assumidos pelos estudantes estão a dedicação integral às atividades acadêmicas e de pesquisa; a apresentação de relatórios com resultados parciais e finais do plano de trabalho; e a participação nos Seminários de Pesquisa e Encontros de Iniciação Científica do ICMBio para a apresentação de seus trabalhos aos comitês avaliadores (COPEG/ICMBIO, 2018).

Os planos de trabalho das pesquisas executadas pelos estudantes atendem as linhas prioritárias de pesquisa estabelecidas nos editais de seleção e apresentam duração de 12 meses. Uma vez submetidos ao PIBIC/ICMBio, eles são avaliados e, caso aprovados, são desenvolvidos pelos estudantes junto às Unidades de Conservação Federais, Centros Nacionais de Pesquisa e Conservação, Coordenações Regionais ou Coordenações da Sede do ICMBio (COPEG/ICMBIO, 2018). 
Não há limite de vagas. No entanto, de acordo com sua classificação, os planos de trabalho aprovados podem conferir bolsas mensais de iniciação científica do $\mathrm{CNPq}^{1}$ (conforme a RN 017 de 2016 do $\mathrm{CNPq}$ ) no valor total de $\mathrm{R} \$ 400,00$ (quatrocentos reais), bolsa de Contrapartida Institucional do ICMBio no valor de $\mathrm{R} \$ 484,00$ (quatrocentos e oitenta e quatro reais) aos estudantes; ou serem desenvolvidos na modalidade voluntária. No caso de alunos bolsistas, os estudantes não podem apresentar vínculo empregatício ou outras bolsas durante a vigência do contrato (COPEG/ICMBIO, 2018).

\section{$\underline{\text { Resultados de } 10 \text { anos de implementação do PIBIC/ICMBio no Brasil }}$}

Desde a implementação do PIBIC/ICMBio em 2008, foram realizados 304 projetos de iniciação científica com a participação de 262 estudantes de graduação, orientados por 84 servidores do ICMBio. Dentre os projetos, $48 \%$ foram desenvolvidos por alunos com bolsa do CNPq, 29\% com bolsa de contrapartida institucional (bolsas do Centro de Integração EmpresaEscola ou CIEE) e $24 \%$ por voluntários.

Dentre os estudantes egressos do Programa, 99\% ( $n=259)$ apresentavam Lattes no momento da realização da presente pesquisa. Eles tiveram como origem 66 diferentes instituições de ensino superior brasileiras e cursaram 21 diferentes cursos de graduação. Com relação aos orientadores, $98 \%(n=82)$ apresentavam Lattes. Eles constituíram servidores de 13 Centros Nacionais de Pesquisa e Conservação do ICMBio, de 30 Unidades de Conservação Federais e de cinco Coordenações da Sede do ICMBio (Figura 2).

\footnotetext{
${ }^{1}$ As bolsas de iniciação científica do CNPq podem ser conferidas apenas a estudantes com orientadores doutores.
} 
Figura 2 - Distribuição das unidades do Instituto Chico Mendes de Conservação da Biodiversidade (ICMBio) participantes do Programa Institucional de Bolsas de Iniciação Científica (PIBIC/ICMBio) Unidades de Conservação Federais, Centros de Pesquisa e Coordenações da Sede e das instituições de ensino superior de origem dos ex-alunos do Programa durante o período de 2008 a 2018

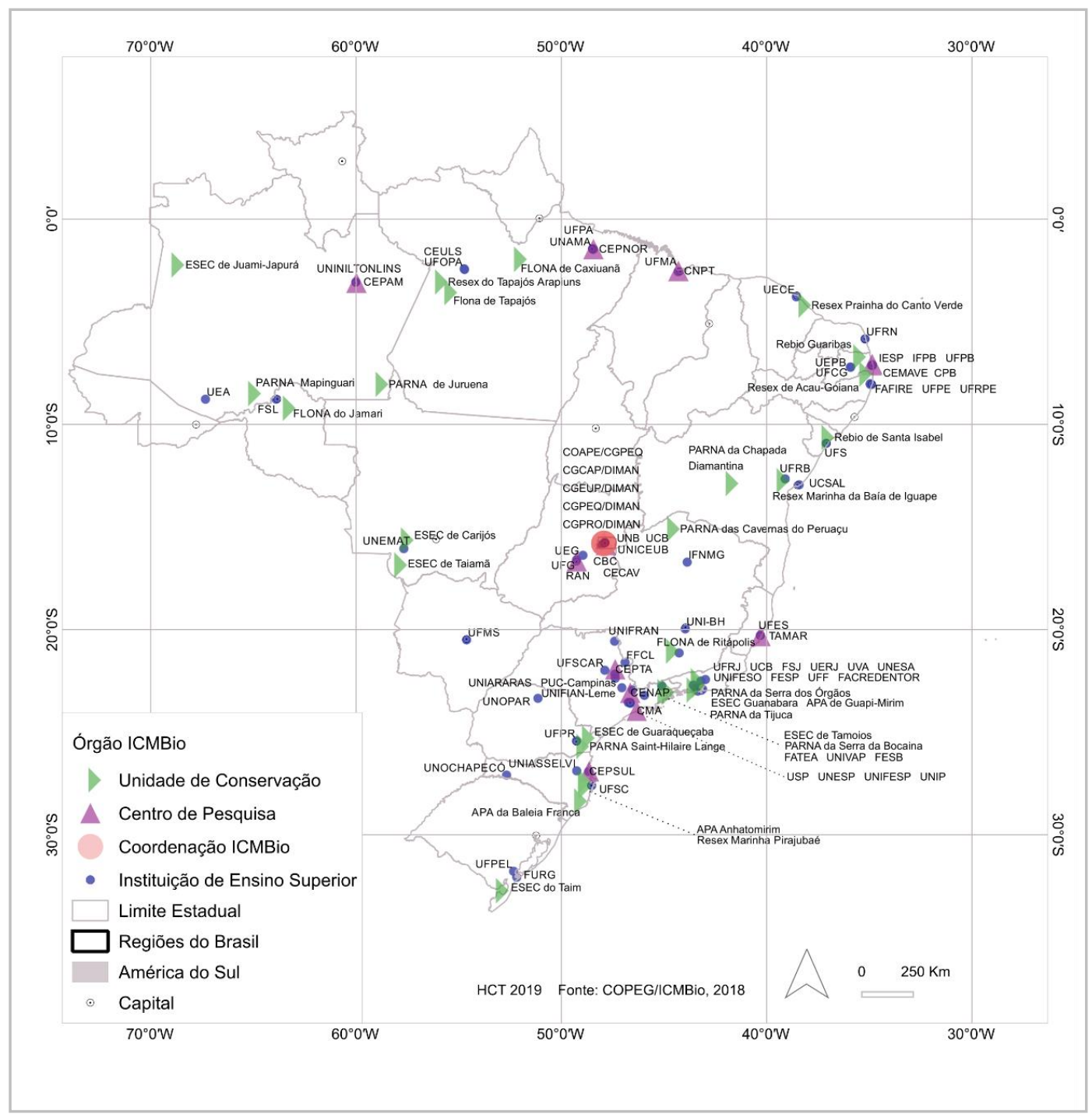

A consulta aos ex-estudantes PIBIC/ICMBio demonstrou que todos apresentaram a percepção de que o estágio no Programa constituiu um incentivo para seu ingresso na carreira científica e para a aquisição de experiência em pesquisa. Segundo eles, a experiência estimulou principalmente suas produções intelectuais para a gestão da biodiversidade, a ampliação das chances de inserção no mercado de trabalho após a graduação e o enriquecimento da qualidade do trabalho profissional após a graduação.

Atualmente a maioria deles apresenta como ocupação a pós-graduação (54\%) e, dentre esses, $61 \%$ apresentam projetos de pesquisa cujos temas constituem, parcial ou totalmente, um desdobramento do plano de trabalho desenvolvido no PIBIC/ICMBio. As outras atividades 
profissionais são professor, profissional autônomo, logística de transporte, empresário, analista/gestor, pesquisador, funcionário público e monitor de pesca.

Para os ex-estudantes PIBIC/ICMBio consultados que ainda cursavam a graduação, a pós-graduação apresentou a maior taxa de pretensão profissional (44\%), seguida pela busca de emprego na área da graduação (28\%) e da preparação para concursos públicos (22\%).

Em acordo com essas declarações, quase metade (44\%) dos ex-alunos PIBIC/ICMBio com currículos cadastrados na Plataforma Lattes do CNPq atualizados em 2018 (n=128) ingressaram na pós-graduação. Desses, à época da consulta, $28 \%$ haviam ingressado no mestrado, $10 \%$ no doutorado e $6 \%$ em cursos de especialização (Figura 3).

Figura 3 - Formação dos ex-alunos do Programa Institucional de Bolsas de Iniciação Científica (PIBIC/ICMBio) do Instituto Chico Mendes de Conservação da Biodiversidade (ICMBio) participantes em cada um dos ciclos de implementação do Programa, de 2008 a 2018, com base na Plataforma Lattes (atualização em 2018, n=128 estudantes egressos)

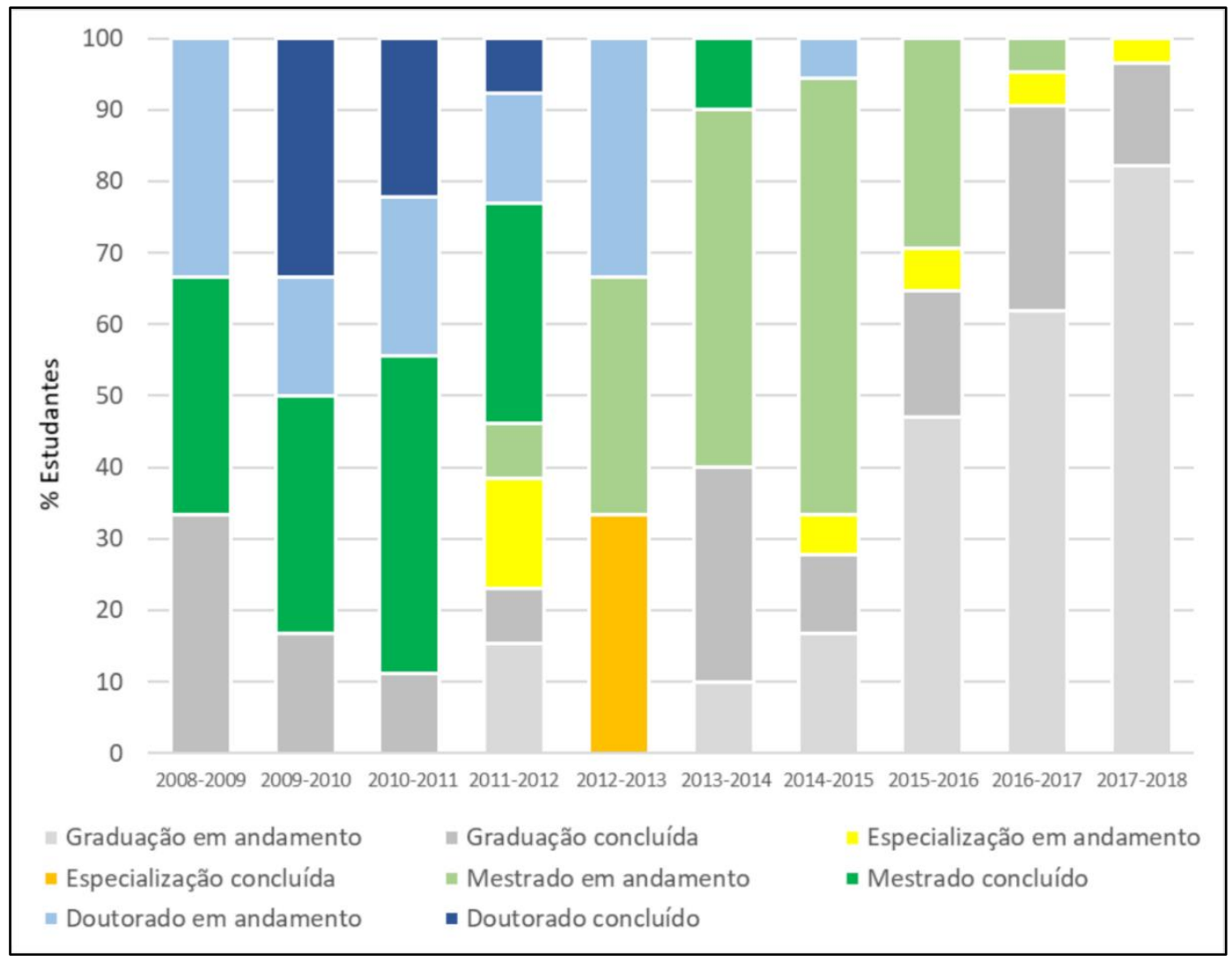

De acordo com a Figura 3, é possível verificar um período de aproximadamente dois e cinco anos passados do estágio PIBIC/ICMBio para identificar ex-alunos no mestrado e no doutorado, respectivamente. Apesar da tendência a cursar mestrado e doutorado em sequência, esta amplitude pode estar relacionada ao fato de o PIBIC/ICMBio selecionar alunos em diferentes semestres dos cursos de graduação. Outros fatores que podem interferir neste período 
são a quantidade de vagas ofertadas e a quantidade de bolsas de pesquisa disponíveis nos cursos de pós-graduação.

Com relação à produção bibliográfica dos ex-estudantes consultados, de acordo com a análise do Lattes, a maior parte correspondeu à publicação de resumos simples e expandidos em anais de congressos $(n=744)$, seguida de apresentações de trabalhos $(n=579)$, artigos publicados ou aceitos em periódicos $(n=190)$ e trabalhos técnicos $(n=147)$. Os ex-estudantes das turmas dos ciclos PIBIC/ICMBio mais antigos apresentaram a maior porcentagem de publicação de artigos científicos publicados ou aceitos em revistas científicas. Por outro lado, a porcentagem de publicações de resumos simples e expandidos em anais de congressos, apresentação de trabalhos e a realização de trabalhos técnicos variou entre os alunos dos ciclos (Figura 4). Dentre eles, estavam incluídos a participação de ex-alunos na elaboração de planos de manejo de unidades de conservação, na elaboração de cartilhas de educação ambiental, de guias de identificação de fauna e flora, de relatórios técnicos sobre consultorias ambientais para empresas, entre outros.

Figura 4 - Produção bibliográfica (\%) de artigos publicados ou aceitos em periódicos (vermelho), resumos simples e expandidos publicados em anais de congressos (amarelo), apresentação de trabalhos (verde) e trabalhos técnicos (azul) de ex-alunos do Programa Institucional de Bolsas de Iniciação Científica (PIBIC/ICMBio) do Instituto Chico Mendes de Conservação da Biodiversidade (ICMBio) participantes em cada um dos ciclos do Programa, de 2008 a 2018, com base na Plataforma Lattes (atualização em 2018, n=128 estudantes egressos)

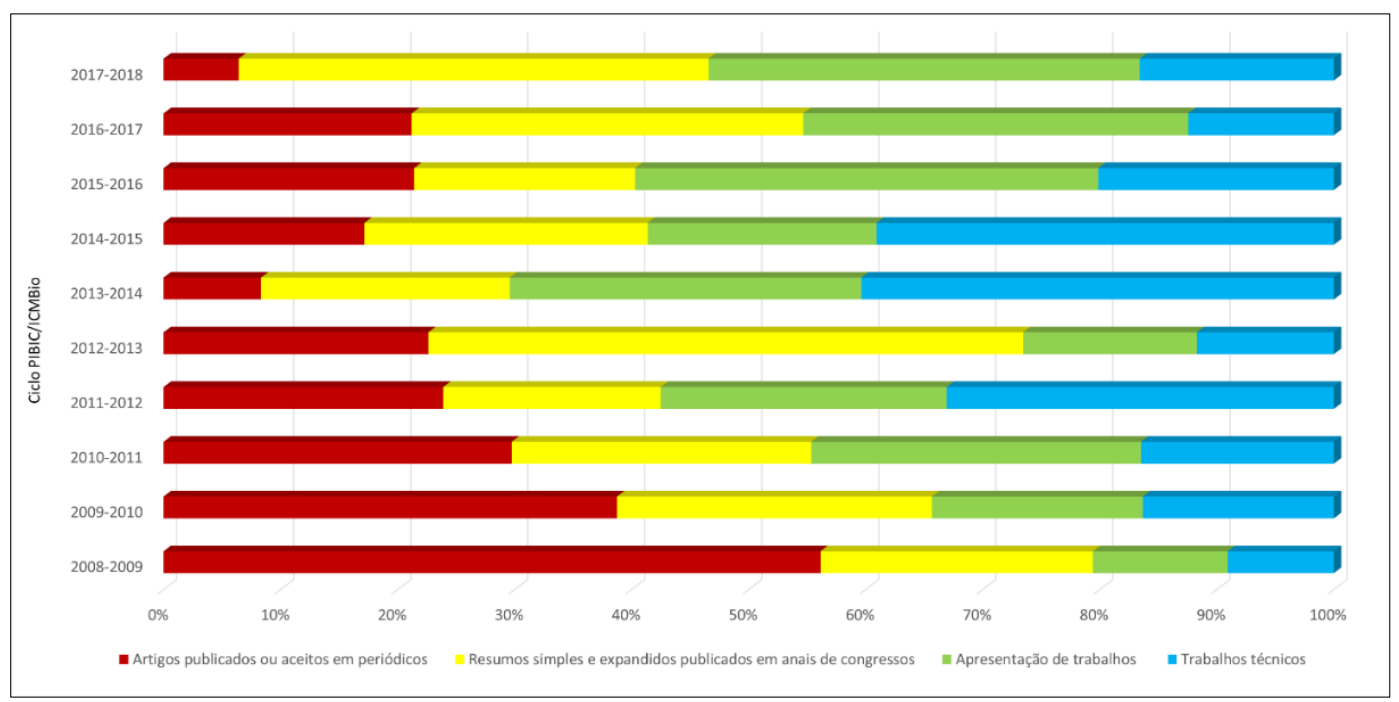

De acordo com os ex-orientadores do PIBIC/ICMBio consultados, todos os projetos de pesquisa dos seus respectivos orientandos contribuíram de alguma forma com a gestão da biodiversidade no país. Como exemplo, $80 \%$ das pesquisas subsidiaram ações de proteção, preservação e conservação da biodiversidade, sendo $75 \%$ nas escalas local a regional e 5\% na 
escala nacional. Além disso, 70\% delas resultaram em desenvolvimento de outras pesquisas relacionadas à gestão da biodiversidade; $40 \%$ resultaram em ações de educação ambiental nas escalas local a regional; 35\% contribuíram com o aprimoramento dos processos de gestão nos órgãos do ICMBio; e 25\% resultaram em ações para atender demandas socialmente relevantes nas escalas local a regional.

Exemplos da relação clara entre pesquisa e ações de manejo e gestão são os estudos de Martins et al. (2015) e de Nicoletti et al. (2013) sobre o monitoramento da fauna atropelada na Estação Ecológica do Taim; de Salles et al. (2017) sobre a presença do coral invasor Tubastrea sp. na Reserva Extrativista Marinha Baía do Iguape; de Brasil e Castro (2015) sobre a relação da dispersão da árvore invasora Artocarpus heterophyllus com a presença humana histórica no Parque Nacional da Tijuca, dentre outros.

No âmbito das políticas públicas brasileiras e de seus instrumentos de gestão para a conservação da biodiversidade, segundo os ex-orientadores do PIBIC/ICMBio consultados, todas as pesquisas do Programa contribuíram, direta ou indiretamente, com a implementação de alguma de suas estratégias. Os planos de manejo de unidade de conservação, a Estratégia Nacional de Biodiversidade (Metas de Aichi) e o Sistema Nacional de Unidades de Conservação foram os mais apontados. Vale destacar que, de acordo com $89 \%$ dos exestudantes consultados, os resultados dessas pesquisas (tais como o resumo do seminário de pesquisa, relatório de pesquisa, tabelas, mapas e outros meios de publicações) foram divulgados, parcial ou totalmente, para outros atores-chave que poderiam utilizá-las, como demais gestores de UC, outros órgãos ambientais, ONGs e demais parceiros. Reafirmando tais colocações, segundo os atores-chave participantes na Oficina Participativa, o PIBIC/ICMBio vem contribuindo diretamente com diversas atribuições do ICMBio.

A análise do cruzamento das finalidades do ICMBio descritas no Decreto $n^{\circ} 8.974$, de 24 de janeiro de 2017 com os trabalhos publicados nos nove Anais dos Seminários de Pesquisa do PIBIC/ICMBio evidenciou que o Programa tem gerado e sistematizado informações relevantes sobre as várias áreas de atuação do Instituto como, por exemplo, na avaliação do estado de conservação e manejo das espécies ameaçadas (CARVALHO et al., 2013); em ações de gestão nas unidades de conservação federais, como Martins et al. (2015) e Nicoletti et al. (2013); sobre a proposição de criação de unidades de conservação federais, como Santos e Roos (2009); sobre a visitação pública voltada à recreação, à interpretação ambiental e ao ecoturismo em UCs, como Barberena et al. (2011); sobre ações de polícia ambiental para a proteção das UCs, como Silva Júnior (2009); sobre famílias extrativistas residentes em UCs de uso sustentável, como Salera Júnior et al. (2013); sobre ações de fiscalização e prevenção e combate 
aos incêndios florestais, como Araki et al. (2013); e sobre licenciamento ambiental, como Santos e Becker (2013).

A avaliação do cruzamento dos critérios dos Editais PIBIC/ICMBio para a avaliação das propostas de projeto, das temáticas dos Seminários de Pesquisa, e dos 14 eixos temáticos previstos no Plano Estratégico de Pesquisa e Gestão do Conhecimento (PEP) 2018-2021 do ICMBio (Portaria n ${ }^{\circ}$ 804, de 19 de setembro de 2018) evidenciou um alinhamento de conteúdo. Como exemplo, o Edital do ciclo 2017-2018 apresentou, como critério de eliminação das propostas, linhas temáticas diretamente relacionadas a 12 eixos do PEP. Além disso, seis deles foram especificamente discutidos no X Seminário de Pesquisa e X Encontro de Iniciação Científica do PIBIC/ICMBio realizado em 2018.

A averiguação do cruzamento das publicações dos nove Anais dos Seminários de Pesquisa do Programa com a atribuição do ICMBio em implementar ações para as metas da Estratégia e Plano de Ação Nacionais para a Biodiversidade (EPANB) evidenciou que o PIBIC/ICMBio contribuiu diretamente com informações para o alcance das Metas Nacionais de Aichi: Meta 1 (Ações 1 e 28), Meta 5 (Ação 3), Meta 6 (Ações 1 e 19), Meta 7 (Ações 10 e 40), Meta 9 (Ações 1 e 15), Meta 10 (Ação 2), Meta 11 (Ações 7, 21, 39 e 63), Meta 12 (Ação 8), Meta 19 (Ações 3, 53 e 70). Além disso, o Programa contribuiu indiretamente com as Metas Nacionais de Aichi 1, 2, 4, 5, 6, 7, 8, 9, 10, 11, 12, 14, 15 e 19, devido à interface de atuação.

No que diz respeito à Estratégia Nacional em Comunicação e Educação Ambiental em Unidades de Conservação (ENCEA), de acordo com os ex-orientadores consultados, $40 \%$ dos planos de pesquisa dos orientandos abordaram a educação ambiental. Exemplos são os trabalhos de Barberena et al. (2011) no Parque Nacional da Chapada Diamantina; de Batista e Nunes (2011) na Floresta Nacional do Tapajós; e de Omena et al. (2014) no Parque Nacional de São Joaquim, dentre outros.

Convém ressaltar que, de acordo com a análise dos projetos PIBIC/ICMBio realizados nesses 10 anos, tanto o Parque Nacional da Tijuca quanto o Parque Nacional da Serra da Bocaina, ambos participantes do PIBIC/ICMBio e incluídos na lista das 10 UCs federais mais visitadas em 2017 (COPEG/ICMBIO, 2018), não desenvolveram projetos PIBIC/ICMBio nesta temática. Considerando que o uso público em unidades de conservação constitui um potencial mecanismo para a conscientização dos visitantes em relação à preservação destas áreas, além de poder contribuir com o desenvolvimento regional, essas UCs constituem potenciais estudos de caso para futuras pesquisas do PIBIC/ICMBio.

No que concerne a coerência da implementação do PIBIC/ICMBio com o objetivo do Conselho Nacional de Desenvolvimento Científico e Tecnológico (CNPq) em "promover e 
fomentar o desenvolvimento científico e tecnológico do país e contribuir na formulação das políticas nacionais de ciência, tecnologia e inovação" (BRASIL, 2016, Art. 1º), a Figura 4 evidencia a relação entre as unidades do ICMBio e as 66 instituições de ensino superior (IES) de origem dos ex-estudantes durante o período de 2008 a 2018. Pode-se perceber dois eixos principais de parcerias acadêmicas do PIBIC/ICMBio, um agregando as regiões sul, sudeste e nordeste e outro entre as regiões norte e sudeste do país. Além deles, quatro pequenos eixos secundários de parcerias científicas são evidenciados no Distrito Federal, no Rio de Janeiro, em São Paulo e no sul do estado de Mato Grosso (Figura 5).

Vale destacar que a rede de IES parceiras do PIBIC/ICMBio compreende desde instituições com Índice Geral de Cursos (IGC) mínimo a máximo. De acordo com a avaliação do Instituto Nacional de Estudos e Pesquisas Educacionais Anísio Teixeira (INEP) do Ministério da Educação (MEC) de 2017, 11\% delas apresentam situação acadêmica excelente (IGC=5), 39\% muito boa (IGC=4), 41\% apresentam situação regular (IGC=3) e 2\% ruim (IGC abaixo de 3).

Tal relação sugere a contribuição do PIBIC/ICMBio no fortalecimento das instituições com IGC regular ou ruim. Exemplos são as pesquisas desenvolvidas pelos alunos do Centro Universitário Serra dos Órgãos (UNIFESO), cujo IGC no último triênio foi 3 e cuja parceria com o Programa tem-se mantido sólida nesses 10 anos. Por outro lado, também aponta a continuidade de parcerias com universidades já consagradas, como a Universidade de São Paulo, a Universidade Federal do Rio de Janeiro e a Universidade de Brasília, dentre outras. 
Figura 5 - Distribuição da relação (quantidade de projetos PIBIC/ICMBio desenvolvidos) entre as unidades do Instituto Chico Mendes de Conservação da Biodiversidade (ICMBio) e as Instituições de Ensino Superior de origem dos ex-alunos do Programa durante o período de 2008 a 2018

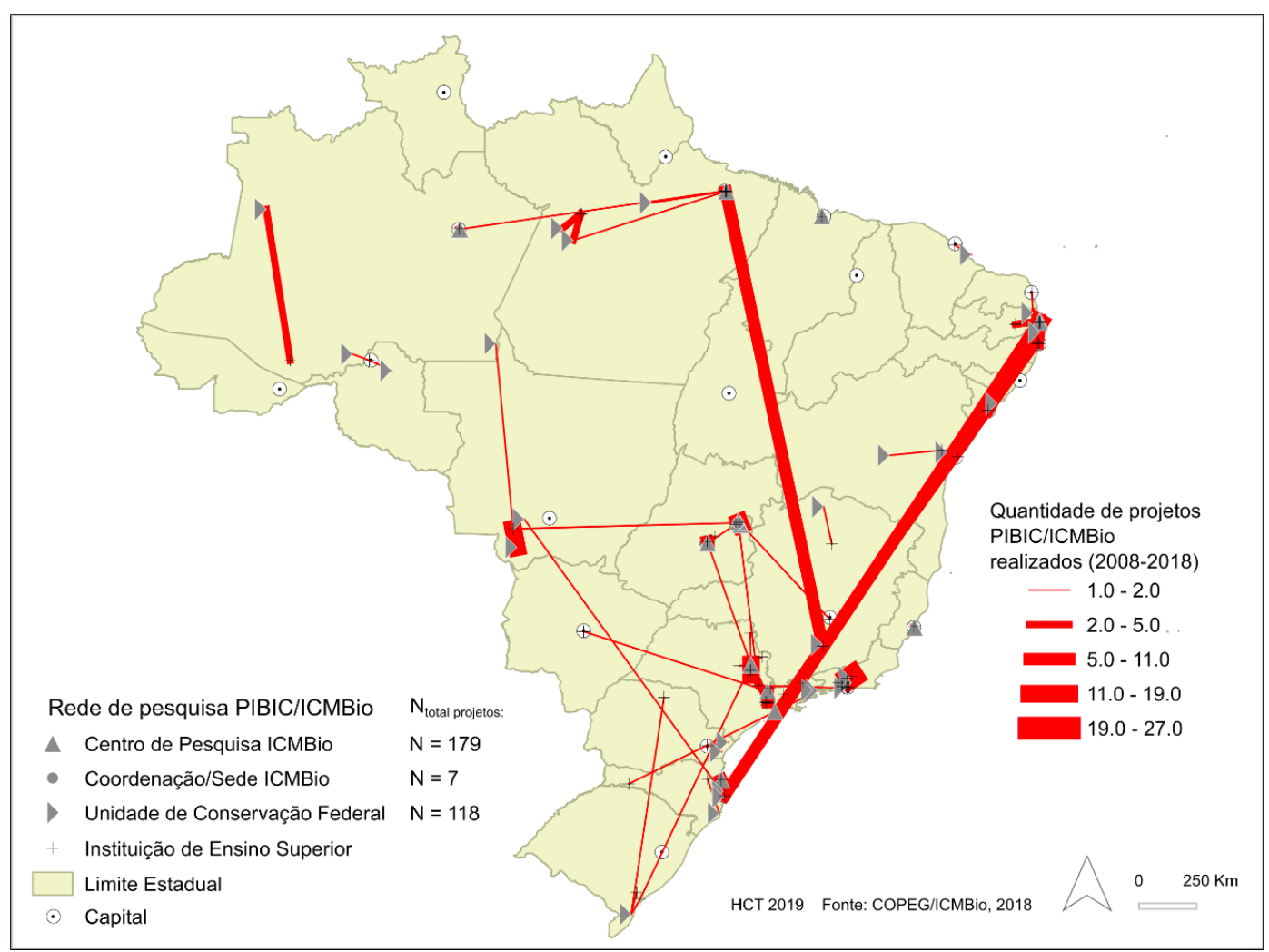

Com relação à contribuição do PIBIC/ICMBio no ingresso de alunos na pós-graduação, observa-se que em 2018, 26\% das unidades de pesquisa do Programa apresentavam ex-alunos com especialização em andamento ou concluída; 45\% apresentavam ex-alunos com mestrado em andamento ou concluído; e 14\% deles apresentavam ex-alunos com doutorado em andamento ou concluído. Em algumas unidades, 100\% dos ex-alunos PIBIC ingressaram na pós-graduação, como é o caso do Parque Nacional Saint-Hilaire/Lange e da Estação Ecológica de Guaraqueçaba, ambas localizadas no estado do Paraná; e da Estação Ecológica Guanabara, localizada no estado de São Paulo (Figura 6).

Considerando a pretensão de ingresso na pós-graduação pelos ex-estudantes PIBIC/ICMBio consultados e suas respectivas percepções sobre a influência do estágio neste processo, a contribuição do Programa poderia ser potencializada por meio do fortalecimento de sua rede de parcerias, tais quais as parcerias acadêmicas e grupos de pesquisa. De acordo com o Lattes, 65\% dos servidores orientadores com Currículo Lattes atualizado em 2018 integravam um a quatro Grupos de Pesquisa do Diretório dos Grupos de Pesquisa do CNPq, reunindo, ao todo, 35 Grupos nacionais. 
Figura 6 - Distribuição da titulação atual dos ex-alunos PIBIC/ICMBio participantes dos ciclos 2008 a 2018 com base na Plataforma Lattes (atualização em 2018, n=128 estudantes egressos)

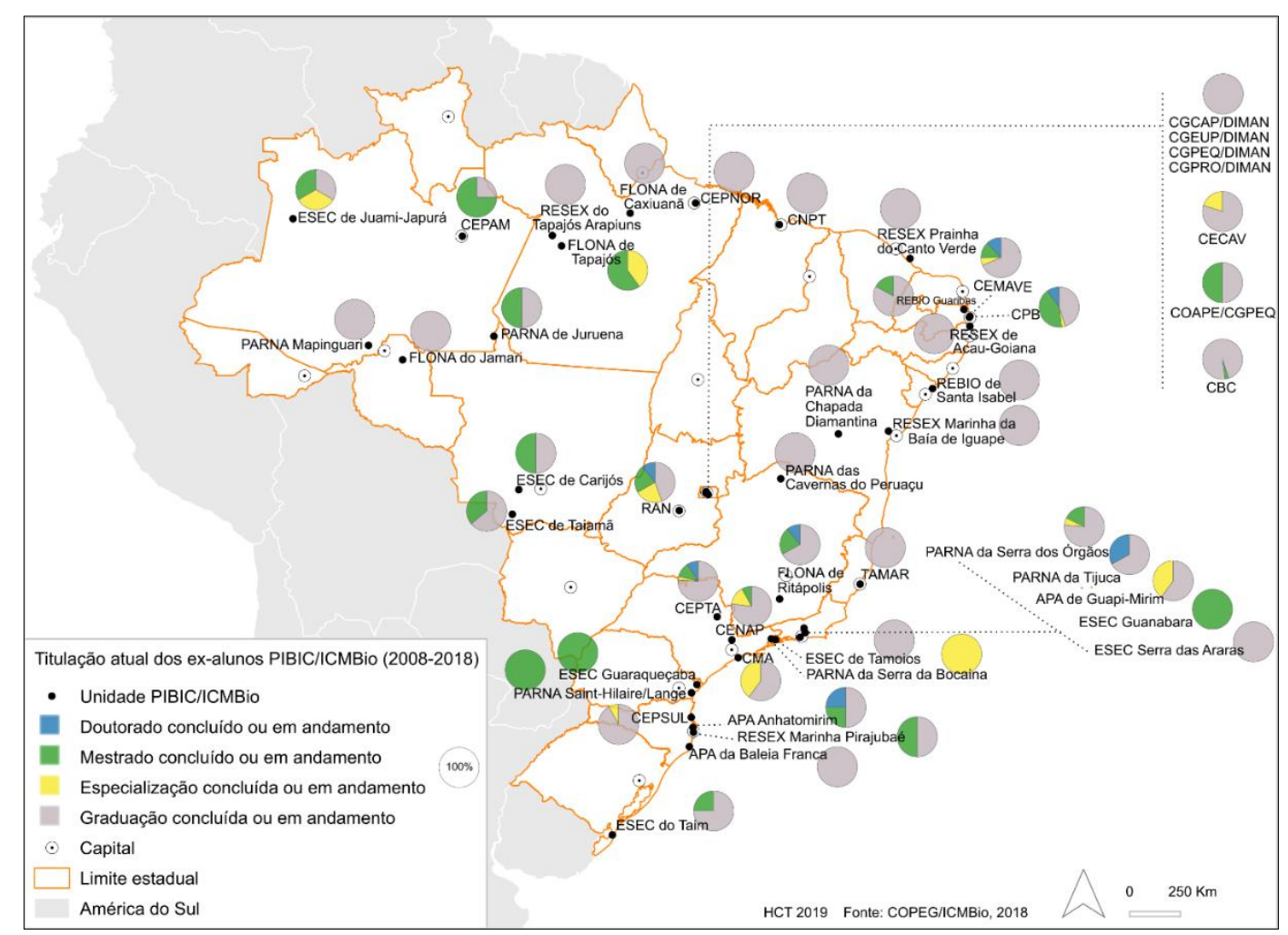

Com relação à formação do quadro de orientadores do PIBIC/ICMBio nos 10 anos de sua implementação, os servidores doutores constituíram a maioria (58\%), apresentaram o dobro de participação nos ciclos de implementação do Programa em relação aos servidores mestres ( $\mathrm{R}=1,39$ e $\mathrm{R}=0,64$, respectivamente) e foram os que mais contribuíram com a produção bibliográfica do Programa (Figura 7).

A análise dos 11 Editais de Seleção do PIBIC/ICMBio evidenciou que o Comitê Institucional do Programa tem se empenhado, desde 2011, em incentivar a participação de servidores mestres por meio da modificação das pontuações dos critérios de titulação dos orientadores e da adequação das propostas (ambos exigidos para a aprovação e ranking dos planos de trabalho). Este fator pode estar relacionado com: i) o perfil atual dos servidores do ICMBio com ensino superior o qual, segundo a Coordenação Geral de Gestão de Pessoas CGGP do ICMBio é de 24\% de mestres e 5\% de doutores (dados de setembro de 2018); e ii) a possibilidade legal e respaldo técnico desses servidores orientarem estudantes com bolsa de contrapartida Institucional e/ou voluntários no PIBIC/ICMBio.

Apesar da relevância desse esforço, é válido apontar a importância de o ICMBio em incentivar o ingresso de seus servidores atuais em cursos de mestrado e doutorado. 
Figura 7 - Distribuição (\%) da produção bibliográfica total dos servidores orientadores do PIBIC/ICMBio com mestrado, com doutorado e com doutorado em andamento no período de 2008-2018 com base na Plataforma Lattes (atualização em 2018, n=82 servidores). Publicações em anais de congressos $=$ trabalhos completos, resumos simples e expandidos

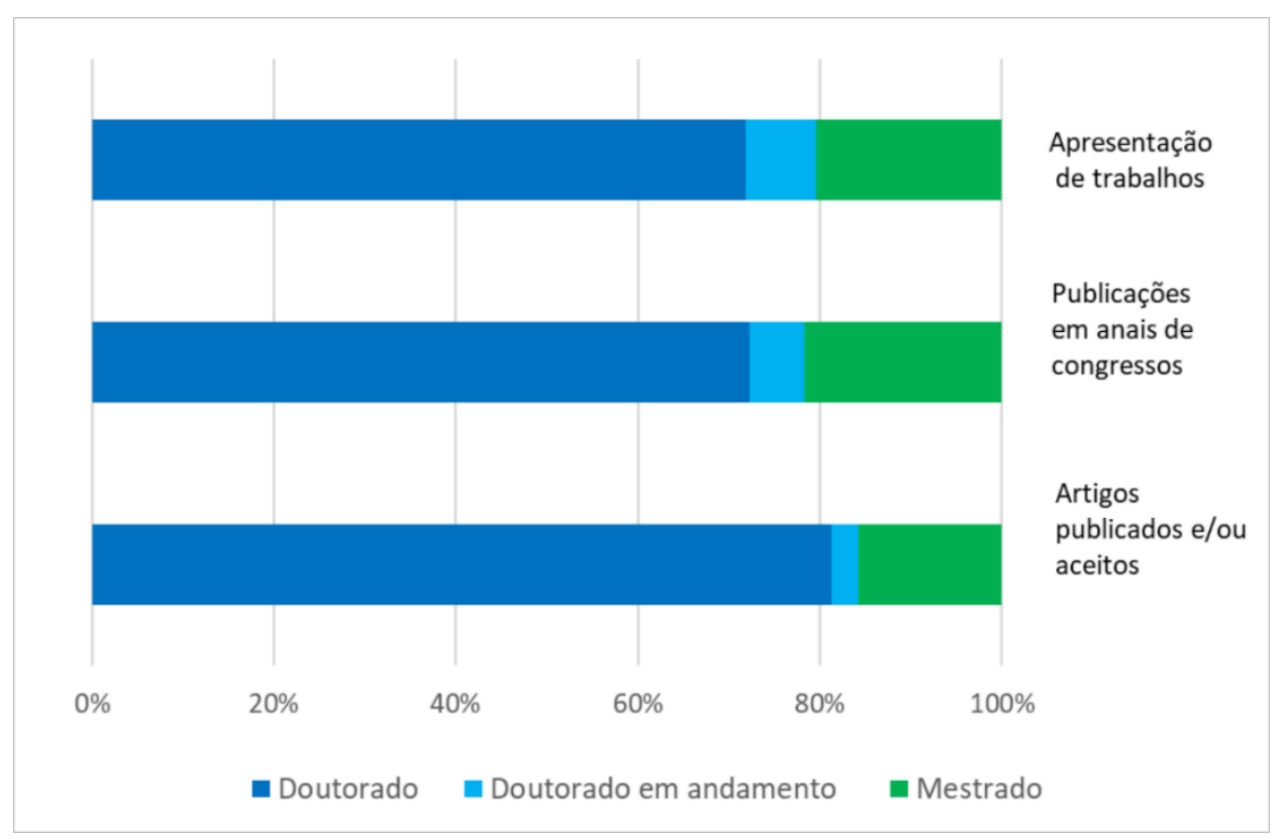

No que concerne os custos envolvidos na implementação do PIBIC/ICMBio, para a sua realização foram investidos em média $\mathrm{R} \$ 433.591,56$ (quatrocentos e trinta e três mil, quinhentos e noventa e um reais e cinquenta e seis centavos) anuais (Quadro 1). De acordo com o Centro de Microeconomia Aplicada da Fundação Getúlio Vargas, este valor anual, se distribuído pelo número médio de estudantes do ciclo anual do PIBIC/ICMBio, corresponde a $45 \%$ do valor gasto com a contratação de um trabalhador brasileiro em regime integral e com salário mínimo no período de 12 meses, cujo investimento anual atual corresponde a $\mathrm{R} \$ 30.079,08$.

Quadro 1 - Discriminação dos custos anuais dos insumos do PIBIC/ICMBio identificados na Cadeia de Resultados

\begin{tabular}{|c|c|}
\hline Insumos & Investimento anual \\
\hline $\begin{array}{c}\text { Recursos financeiros para bolsas de iniciação científica aos } \\
\text { estudantes }\end{array}$ & $\mathrm{R} \$ 173.520,00$ \\
\hline $\begin{array}{c}\text { Seguro de vida } \\
\text { Programa }\end{array}$ & $\mathrm{R} \$ 710,16$ \\
\hline $\begin{array}{c}\text { Salário de servidores responsáveis pela administração do } \\
\text { encontros científicos } \\
\text { Recursos financeiros para a realizac̃o de seminários e }\end{array}$ & $\mathrm{R} \$ 160.001,40$ \\
\hline $\begin{array}{c}\text { Infraestrutura dos órgãos do ICMBio para o desenvolvimento } \\
\text { de pesquisa e realização de encontros científicos }\end{array}$ & --- \\
\hline $\begin{array}{c}\text { Salário de servidores responsáveis pela orientação dos } \\
\text { estudantes } \\
\text { Total }\end{array}$ & $\mathrm{R} \$ 433.591,56$ \\
\hline
\end{tabular}

Fonte: COPEG/ICMBIO, 2018. 
A análise das contribuições dos projetos desenvolvidos pelos estudantes de iniciação científica do PIBIC/ICMBio em relação aos seus respectivos custos evidencia que os resultados não apenas sustentam sua implementação, como sinalizam uma positiva e considerável relação custo-benefício. De acordo com o conjunto de atores-chave do PIBIC/ICMBio participantes do presente estudo, o financiamento de bolsas de pesquisas para estudantes é primordial para que um grupo de pesquisa adquira experiência, destaque e liderança científica e tecnológica para a gestão da biodiversidade no Brasil.

No entanto, além dela, outro elemento fundamental é a disponibilização de recursos financeiros para a realização das pesquisas em si, tais quais editais para projetos guarda-chuva dos orientadores. É importante mencionar que de acordo com o estudo de Salzo (2014) os analistas do ICMBio são favoráveis à implementação de um sistema de fomento e apoio a projetos de pesquisa e monitoramento nas unidades do Instituto. Como exemplo, segundo o COPEG/ICMBio (2018), a Chamada Interna de Projetos (CIP), realizada pelo Instituto no período de 2010 a 2015 e extinta devido à ausência de recursos, os possibilitava incluir as pesquisas no planejamento institucional das unidades.

$\mathrm{Na}$ opinião dos participantes da Oficina Participativa do PIBIC/ICMBio, potenciais parceiros para a disponibilização de recursos a projetos e bolsas de pesquisa ao Programa poderiam ser o Ministério do Meio Ambiente e projetos especiais; Fundações Estaduais de Apoio a Pesquisa; o Ministério de Ciência, Tecnologia e Informação e o CNPq; ONGs e Fundações de apoio à pesquisa, entre outros.

A análise contrafactual da existência do PIBIC/ICMBio para o Instituto indicou que em sua ausência, haveria: perda da oportunidade de qualificação dos servidores como pesquisadores, orientadores e gestores; perda de um importante locus de intercâmbio entre servidores do ICMBio, por conta do seminário de pesquisa; perda da única ferramenta, atualmente disponível, de apoio financeiro direto à pesquisa, protagonizada por servidores do ICMBio; perda da oportunidade de geração de impactos positivos junto à sociedade; perda do papel educativo dos servidores orientadores de iniciação científica; desestímulo aos servidores do ICMBio para a realização de pesquisa; enfraquecimento da integração do ICMBio com a academia; enfraquecimento do suporte técnico-científico às decisões de gestão do ICMBio; diminuição da oferta de oportunidade de atividade à população local; perda de apoio a atividades das unidades do ICMBio, tal qual a perda de apoio operacional; enfraquecimento da pesquisa aplicada para a conservação da biodiversidade; diminuição de pesquisas sobre conservação em unidades de conservação; ausência de pesquisas prioritárias e inovadoras para 
a conservação e gestão da biodiversidade que advêm de perguntas diretamente associadas às demandas de gestão; e perda de oportunidades de geração de dados que embasam a gestão socioambiental nas diferentes escalas territoriais.

De acordo com os atores-chave participantes da Oficina Participativa do PIBIC/ICMBio, o Programa é capaz de criar sementes científicas em uma área de gestão ambiental pública na qual nem os graduandos teriam normalmente o acesso tão direto na academia para gerar conhecimento para subsidiar diretamente ações de gestão, nem os gestores do ICMBio teriam, em geral, disponibilidade de dedicação para investigar respostas para as demandas do exercício de sua atividade.

O processo fortalece tanto o papel dos gestores do Instituto na condução e aperfeiçoamento técnico e científico das pesquisas aplicadas à resolução de problemas, quanto contribui com o avanço do conhecimento, com a formação e com a ampliação do sistema científico e tecnológico brasileiro, principalmente na formação de recursos humanos. Além disso, gera informações cruciais para o entendimento e manutenção da biodiversidade brasileira. De forma indireta, contribui com o fortalecimento dos parceiros envolvidos, além de favorecer a implementação de outras políticas públicas.

\section{Conclusão}

A análise de evidências do PIBIC/ICMBio apontou que o arranjo de suas iniciativas permitiu o alcance de todos os seus objetivos nesses 10 anos de implementação, demonstrando sua efetividade. O Programa tem contribuído com a ampliação do conhecimento sobre a biodiversidade tanto pelo envolvimento de servidores e estudantes na rede de pesquisa para a conservação, quanto pelas suas participações nos Seminários Anuais de Pesquisa e Encontros de Iniciação Científica.

A curto e médio prazo, o Programa contribuiu com o desenvolvimento de projetos que: i) estimularam os estudantes a ingressarem na pós graduação; ii) estimularam a produção bibliográfica dos estudantes e servidores, como resumos simples e expandidos em anais de congressos, apresentações de trabalhos, artigos e trabalhos técnicos; iii) aprimoraram a gestão local das unidades de conservação; e iv) estimularam e atualizaram os servidores do ICMBio na atuação como pesquisadores para a conservação, os quais atualmente integram grupos de pesquisa e engajam os estudantes na rede de pesquisa do PIBIC/ICMBio.

Legay (2006a, 2006b) denomina esta produção como ciência eficaz, uma vez que é associada a instrumentos ou argumentos de apoio à decisão, com vistas a um uso prático para 
gestores, autoridades locais e em apoio a políticas públicas. Barlow et al. (2018) complementam que ela tem um papel vital para aumentar a capacidade de governança, uma vez que é capaz de impulsionar a inovação e o desenvolvimento de soluções baseadas em evidências e, desta forma, permitir a concepção de ações concretas de conservação. Os autores chamam a atenção para a sua necessidade nos trópicos, onde a diversidade ecológica, a vulnerabilidade e a complexidade socioeconômica exigem o pluralismo e abordagens complementares e sinérgicas na gestão da biodiversidade.

Outros autores que enfatizam a importância da pesquisa aplicada para a gestão e manejo da biodiversidade brasileira são Tozato (2015, 2016), Salzo (2014), Madeira et al. (2008), Castro e Cronemberger (2007), Garay e Becker (2006), Castro (2004), dentre outros.

A médio e longo prazo, o PIBIC/ICMBio contribuiu tanto com a formação de profissionais no campo da gestão socioambiental no Brasil quanto com a consolidação da política de pesquisa e desenvolvimento científico e tecnológico do ICMBio. Os dados do presente estudo demonstram a relevância do Programa para o Instituto alcançar suas demais finalidades previstas no Decreto $\mathrm{n}^{\mathrm{o}}$ 8.974, de 24 de janeiro de 2017. Além disso, o PIBIC/ICMBio apresenta consonância e relevância com a implementação do Plano Estratégico de Pesquisa e Gestão do Conhecimento - PEP (ICMBio, 2018). Outra averiguação foi em relação à coerência do PIBIC/ICMBio com a Estratégia e Plano de Ação Nacionais para a Biodiversidade (EPANB), com o Conselho Nacional de Desenvolvimento Científico e Tecnológico (CNPq) e com a Estratégia Nacional em Comunicação e Educação Ambiental em Unidades de Conservação (ENCEA).

Por fim, no que diz respeito à análise dos custos envolvidos na implementação do PIBIC/ICMBio para atingir seus resultados, os dados levantados no presente estudo comprovam sua eficiência e apontam sua potencialidade. Certamente o arranjo entre os insumos da cadeia de resultados do PIBIC/ICMBio (recursos financeiros para bolsas de iniciação científica, recursos financeiros para seminários, servidores do ICMBio atuantes na orientação de estudantes e na gestão institucional do Programa e infraestrutura dos órgãos do ICMBio para o desenvolvimento de pesquisa e realização de encontros científicos apontados no Quadro 1 constitui o efeito causal para o alcance dos resultados do Programa.

Outros três fatores que impulsionaram esse arranjo foram o caráter participativo do ICMBio, como um órgão de gestão atuando na ponte entre a sociedade e a implementação das políticas públicas ambientais brasileiras; sua capilaridade territorial no país, atuando em todas as regiões e biomas brasileiros; e a especialização técnica de seu quadro de funcionários, os 
quais atuam na resolução de problemas de sociedade-meio ambiente que exigem atividades que ultrapassam o marco acadêmico interdisciplinar.

Considerando os desdobramentos do PIBIC/ICMBio no favorecimento da implementação de outras atribuições do ICMBio bem como de outras políticas públicas brasileiras, a potencialidade de ampliação de seus resultados deve ser considerada. É importante mencionar que o ICMBio é responsável pela gestão de 14 centros nacionais de pesquisa e conservação e de 334 unidades de conservação na esfera federal, as quais correspondem a cerca de $10 \%$ do continente e $26 \%$ do território marinho brasileiro; pela elaboração de estratégias de conservação de espécies da fauna brasileira, especialmente as ameaçadas de extinção; e pela gestão do patrimônio espeleológico a partir de avaliações de risco.

O PIBIC/ICMBio poderia torna-se um eixo integrador para a gestão do conhecimento brasileiro sobre conservação e manejo da biodiversidade, especialmente no que diz respeito ao know-how de apoio à tomada de decisão, com conclusões propositivas capazes de fornecer recomendações para subsidiar planos, programas e projetos socioambientais no país.

Para tanto, vale destacar que além do fortalecimento dos atuais fatores causais de desempenho do Programa, outro elemento fundamental seria a disponibilização de recursos financeiros para a realização das pesquisas em si, tais quais editais para projetos guarda-chuva dos servidores orientadores. Alguns potenciais parceiros para a disponibilização de recursos a projetos e bolsas foram apontados pelos próprios atores-chave. Além deles, outras potenciais fontes de financiamento poderiam vir das cooperações previstas na EPANB para o cumprimento das Metas Nacionais de Aichi.

\section{Agradecimentos}

Ao Projeto PNUD BRA/08/023 e ao Conselho Nacional de Desenvolvimento Científico e Tecnológico $(\mathrm{CNPq})$ pelo apoio financeiro e a todos os atores-chave que gentilmente cederam o seu tempo para contribuir com o presente estudo.

\section{Referências}

ARAKI, Eduardo et al. Zoneamento do risco de incêndio florestal para o Parque Nacional de São Joaquim - SC. In: SEMINÁRIO DE PESQUISA E ENCONTRO DE INICIAÇÃO CIENTÍFICA DO INSTITUTO CHICO MENDES DE CONSERVAÇÃO DA BIODIVERSIDADE, 5., 2013, Brasília. Anais [...]. Brasília: ICMBio, 2013. p. 114. Disponível em: https://www.icmbio.gov.br/portal/images/stories/o-quefazemos/7outANAISVSPIC2013.pdf. Acesso em: 10 out. 2018. 
ARCHELA, Rosely; THÉRY, Hervé. Orientação metodológica para construção e leitura de mapas temáticos. Confins, Londrina, v. 3, p. 1-21, 2008.

BARBERENA, Iara et al. Visitação na cachoeira da fumaça na semana santa e a reação dos grupos de visitantes a ações de esclarecimento sobre normas ambientais. In: SEMINÁRIO DE PESQUISA E INICIAÇÃO CIENTÍFICA DO INSTITUTO CHICO MENDES DE CONSERVAÇÃO DA BIODIVERSIDADE, 3., 2011, Brasília. Anais [...]. Brasília: ICMBio, 2011. p. 132. Disponível em: https://www.icmbio.gov.br/portal/pesquisa/seminarios-de-pesquisa. Acesso em: 10 out. 2018.

BARLOW, Jos et al. The future of hyperdiverse tropical ecosystems. Nature, California, v. 559, p. 517-526, 2018.

BATISTA, Cristina; NUNES, Cíntia. Gestão aplicada dos dados de uso público na Floresta Nacional do Tapajós (PA). In: SEMINÁRIO DE PESQUISA E INICIAÇÃO CIENTÍFICA DO INSTITUTO CHICO MENDES DE CONSERVAÇÃO DA BIODIVERSIDADE, 3. 2011, Brasília. Anais [...]. Brasília: ICMBio, 2011. p. 52. Disponível em: https://www.icmbio.gov.br/portal/pesquisa/seminarios-de-pesquisa. Acesso em: 10 out. 2018.

BAYLIS, Kathy et al. Mainstreaming Impact Evaluation in Nature Conservation.

Conservation Letters, Estados Unidos, v. 9, n. 1, p. 58-64, 2016.

BRASIL, Lucas; CASTRO, Ernesto. O impacto das espécies exóticas e invasoras no Parque Nacional da Tijuca: inventário da ocorrência de gramíneas e de Artocarpus heterophillus Lam. In: SEMINÁRIO DE PESQUISA E ENCONTRO DE INICIAÇÃO CINETÍFICA DO INSTITUTO CHICO MENDES DE CONSERVAÇÃO DA BIODIVERSIDADE, 7., 2015, Brasília. Anais [...]. Brasília: ICMBio, 2015. p. 68. Disponível em: https://www.icmbio.gov.br/portal/pesquisa/seminarios-de-pesquisa. Acesso em: 10 out. 2018.

BRASIL. Presidência da República. Decreto no 8.866, de 3 de outubro de 2016. Aprova o Estatuto do Conselho Nacional de Desenvolvimento Científico e Tecnológico - CNPq, Brasília, 2016.

BRASIL. Portaria ICMBio no 79, de 06 de outubro de 2008. Estabelece o Programa Institucional de Bolsas de Iniciação Científica do Instituto Chico Mendes - PIBIC/ICMBIO. Disponível em: https://www.normasbrasil.com.br/norma/portaria-79-2008_205569.html. Acesso em: Acesso em: 1 out. 2018.

CARVALHO, Tatiane et al. Área de vida e dieta do cachorro-vinagre (Speothos venaticus) no Cerrado, Nova Xavantina (MT). In: SEMINÁRIO DE PESQUISA E INICIAÇÃO CIENTÍFICA DO INSTITUTO CHICO MENDES DE CONSERVAÇÃO DA BIODIVERSIDADE, 5., 2013, Brasília. Anais [...]. Brasília: ICMBio, 2013. p. 31. Disponível em: https://www.icmbio.gov.br/portal/pesquisa/seminarios-de-pesquisa. Acesso em: 10 out. 2018 .

CASTRO, Ernesto; CRONEMBERGER, Cecília. Da ciência ao manejo: o conhecimento científico e a gestão da pesquisa no Parque Nacional Serra dos Órgãos. In: CRONEMBERGER, Cecília; CASTRO, Ernesto. Ciência e conservação na Serra dos Órgãos. Brasília: IBAMA, p. 27-38, 2007. 
CASTRO, Paula. Ciência e Gestão em Unidades de Conservação: o caso do Parque Estadual Turístico do Alto Ribeira (PETAR), SP. 2004. 131p. Dissertação (Mestrado) UNICAMP, Campinas, 2004.

COORDENAÇÃO DE PESQUISA E DE GESTÃO DA INFORMAÇÃO SOBRE BIODIVERSIDADE (COPEG/ICMBIO). Monitoramento anual do PIBIC/ICMBIO. Brasília, 2018.

CONVENTION ON BIOLOGICAL DIVERSITY (CBD). Tools to evaluate the effectiveness of policy instruments for the implementation of the Strategic Plan For Biodiversity 2011-2020. Montreal, 2017.

EUROPEAN COMMISSION (EU). Commission staff working document fitness check of the EU Nature Legislation (Birds and Habitats Directives). Sweden, 2016.

GARAY, Irene; BECKER, Bertha. As dimensões humanas da biodiversidade. O desafio de novas relações sociedade-natureza no século XXI. Petrópolis: Vozes, 2006.

GERTLER, Paul et al. Avaliação de Impacto na prática. 2. ed. Washington D.C: Banco Mundial, 2018.

GIL, Antonio Carlos. Métodos e técnicas de pesquisa social. São Paulo: Atlas, 1987.

INKSCAPE. An Open Source vector graphics editor using the W3C standard Scalable Vector Graphics (SVG) file format. 2018. Disponível em: https://inkscape.org/pt-br/. Acesso em: 10 out. 2018.

INSTITUTO CHICO MENDES DE CONSERVAÇÃO DA BIODIVERSIDADE (ICMBIO). Impacto das Chamadas Internas de Projetos, Produto 2 - Oficina para o estabelecimento de diretrizes de editais como ferramenta de apoio à pesquisa. Brasília, 2018.

KUEFFER, Christoph et al. Enabling Effective Problem-oriented Research for Sustainable Development. Ecology and Society, Nova Scotia, v. 17, p. 4-8, 2012.

LEGAY, Jean-Marie. Interdisciplinarité et biodiversité: un grand défi. In: LEGAY, JeanMarie (org.). L'interdisciplinarité dans les sciences de la vie. Paris: Editions Quæ Indisciplines, 2006a, p. 115-121.

LEGAY, Jean-Marie. La conservation et la gestion de la biodiversité: un défi pour l'interdisciplinarité. In: LEGAY, Jean-Marie (org.). L'interdisciplinarité dans les sciences de la vie. Paris: Editions Quæ Indisciplines, 2006b. p. 151-169.

MADEIRA, João et al. Distribuição espacial do esforço de pesquisa biológica na Serra do Cipó, Minas Gerais: subsídios ao manejo das unidades de conservação da região.

Megadiversidade, Brasília, v. 4, p. 233-247, 2008.

MARTINS, Bianca et al. Monitoramento do padrão de tráfego da rodovia BR471 - ESEC do Taim e seus impactos sobre a fauna silvestre. In: SEMINÁRIO DE PESQUISA E ENCONTRO DE INICIAÇÃO CIENTÍFICA DO INSTITUTO CHICO MENDES DE CONSERVAÇÃO DA BIODIVERSIDADE, 7., 2015, Brasília. Anais [...]. Brasília: 
ICMBio, 2015. p. 66. Disponível em: https://www.icmbio.gov.br/portal/pesquisa/seminariosde-pesquisa. Acesso em: 10 out. 2018.

MASSARDIER, Gilles. Des rationalités multiples enchevêtrees modéle des ajustements mutuels. In: MASSARDIER, Gilles. Politiques et actions publiques. Paris: Armand Colin, 2003, p. 76-85.

MAY, Tim. Pesquisa social: questões, métodos e processos. Porto Alegre: Artmed, 2011.

MINAYO, Maria. Pesquisa social: teoria e método. Petrópolis: Vozes, 2002.

MINAYO, Maria. Pesquisa social: teoria, método e criatividade. Petrópolis: Vozes, 2011.

MOREIRA, Sonia. Análise documental como método e como técnica. In: DUARTE, Jorge; BARROS, Antonio (org.). Métodos e técnicas de pesquisa em comunicação. São Paulo: Atlas, 2005. p. 269-279.

NICOLETTI, Marianni et al. Avaliação da efetividade do sistema de proteção à fauna existente na rodovia BR471 - Esec do Taim. In: SEMINÁRIO DE PESQUISA E ENCONTRO DE INICIAÇÃO CIENTÍFICA DO INSTITUTO CHICO MENDES DE CONSERVAÇÃO DA BIODIVERSIDADE, 5., 2013, Brasília. Anais [...]. Brasília: ICMBio, 2013. p. 26. Disponível em: https://www.icmbio.gov.br/portal/pesquisa/seminarios-depesquisa. Acesso em: 10 out. 2018.

OMENA, Michel et al. Parque Nacional de São Joaquim: do papel à realidade - uma proposta para a gestão do uso público. In: SEMINÁRIO DE PESQUISA E ENCONTRO DE INICIAÇÃO CIENTÍFICA DO INSTITUTO CHICO MENDES DE CONSERVAÇÃO DA BIODIVERSIDADE, 6., 2014, Brasília. Anais [...]. Brasília: ICMBio, 2014. p. 65. Disponível em: https://www.icmbio.gov.br/portal/pesquisa/seminarios-de-pesquisa. Acesso em: 10 out. 2018 .

PRATES, Ana Paula; IRVING, Marta. Conservação da biodiversidade e políticas públicas para as áreas protegidas no Brasil: desafios e tendências da origem da CDB às metas de Aichi. Revista Brasileira de Políticas Públicas, Brasília, v. 5, n. 1, p. 28-57, 2015. Disponível em: https://www.publicacoesacademicas.uniceub.br/RBPP/article/view/3014. Acesso em: $10 \mathrm{dez}$. 2018.

QGIS. A Free and Open Source Geographic Information System. 2018. Disponível em: https://www.qgis.org/pt_BR/site/. Acesso em: 10 out. 2018.

SALERA JÚNIOR, Giovanni et al. Avaliação da atuação dos agentes comunitários de saúde da Reserva Extrativista Mapuá, Ilha de Marajó, Estado do Pará. In: SEMINÁRIO DE PESQUISA E ENCONTRO DE INICIAÇÃO CIENTÍFICA DO INSTITUTO CHICO MENDES DE CONSERVAÇÃO DA BIODIVERSIDADE, 5., 2013, Brasília. Anais [...]. Brasília: ICMBio, 2013. p. 22. Disponível em:

https://www.icmbio.gov.br/portal/pesquisa/seminarios-de-pesquisa. Acesso em: 10 out. 2018.

SALLES, Paulo et al. Diagnóstico da invasão por coral sol (Tubastraea spp.) associada a impactos de grandes empreendimentos em ambientes estuarinos da Resex Marinha Baía do Iguape, Recôncavo Baiano. In: SEMINÁRIO DE PESQUISA E ENCONTRO DE 
INICIAÇÃO CIENTÍFICA DO INSTITUTO CHICO MENDES DE CONSERVAÇÃO DA BIODIVERSIDADE, 9., 2017, Brasília. Anais [...]. Brasília: ICMBio, 2017. p. 67. Disponível em: https://www.icmbio.gov.br/portal/pesquisa/seminarios-de-pesquisa. Acesso em: 10 out. 2018 .

SALZO, Ivan. Avaliação do apoio à pesquisa nas unidades do Instituto Chico Mendes de Conservação da Biodiversidade: subsídios para a gestão estratégica. 116p. Dissertação (Mestrado) - Instituto de Pesquisas Jardim Botânico do Rio de Janeiro, 2014. Disponível em: http://ava.icmbio.gov.br/mod/data/view.php?d=4\&rid=495. Acesso em: 10 out. 2018.

SANTOS, Danilo; ROOS, Andrei. Banco de dados sobre aves brasileiras ameaçadas de extinção: atualização dos mapas de distribuição e avaliação da importância das unidades de conservação. In: SEMINÁRIO DE PESQUISA E INICIAÇÃO CIENTÍFICA DO INSTITUTO CHICO MENDES DE CONSERVAÇÃO DA BIODIVERSIDADE, 1., 2009, Brasília. Anais [...]. Brasília: ICMBio, 2009. p. 46. Disponível em:

https://www.icmbio.gov.br/portal/pesquisa/seminarios-de-pesquisa. Acesso em: 10 out. 2018.

SANTOS, Lucio; BECKER, Fernando. Conectividade de hábitat em bacias hidrográficas: simulações com múltiplas barragens e hierarquia de segmentos para conservação. In: SEMINÁRIO DE PESQUISA E ENCONTRO DE INICIAÇÃO CIENTÍFICA DO INSTITUTO CHICO MENDES DE CONSERVAÇÃO DA BIODIVERSIDADE, 5., 2013, Brasília. Anais [...]. Brasília: ICMBio, 2013. p. 47. Disponível em: https://www.icmbio.gov.br/portal/pesquisa/seminarios-de-pesquisa. Acesso em: 10 out. 2018.

SILVA JÚNIOR, José Martins. Projeto Golfinho Rotador: um programa pesquisa, conservação e manejo de golfinhos em Fernando de Noronha. In: SEMINÁRIO DE PESQUISA E INICIAÇÃO CIENTÍFICA DO INSTITUTO CHICO MENDES DE CONSERVAÇÃO DA BIODIVERSIDADE, 1., 2009, Brasília. Anais [...]. Brasília: ICMBio, 2009. p. 26. Disponível em: https://www.icmbio.gov.br/portal/pesquisa/seminariosde-pesquisa. Acesso em: 10 out. 2018.

THÉRY, Hervé. Présentation détaillée du projet scientifique Territoires et mondialisation dans les pays du Sud, Projet d'Unité Mixte de Recherche. Paris: Institut de Recherche pour le Développement, École Normale Supérieure, 1999. TOZATO, Heloisa. Impactos das mudanças climáticas na biodiversidade das zonas úmidas: uma análise sobre políticas públicas e gestão no Brasil e da França. 409p. Tese em cotutela (Doutorado) - Programa de Pós-Graduação em Ciência Ambiental, Universidade de São Paulo, São Paulo, Doctorat en Géographie, Université de Rennes 2, Rennes (França), 2015. Disponível em: https://teses.usp.br/teses/disponiveis/106/106132/tde-02032016081209/pt-br.php. Acesso em: 5 nov. 2018.

TOZATO, Heloisa. Gestão da biodiversidade na União Europeia: o Programa Natura 2000 como instrumento para o alcance da Meta 11 de Aichi. Revista Gestão \& Políticas Públicas, São Paulo, v. 6, n. 2, p. 164-184, 2016. Disponível em:

http://www.revistas.usp.br/rgpp/article/view/144320. Acesso em: 10 nov. 2018.

WHITE, Howard. Theory-based impact evaluation: principles and practice. Journal of Development Effectiveness, Londres, v. 1, n. 3, p. 271-284, 1999. Disponível em: https://www.tandfonline.com/doi/abs/10.1080/19439340903114628. Acesso em: 10 nov. 2018. 